\title{
mTOR inhibition improves fibroblast growth factor receptor targeting in hepatocellular carcinoma
}

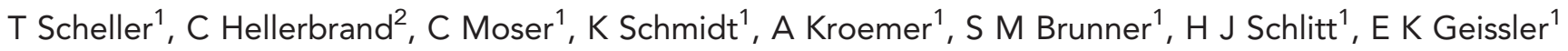 \\ and S A Lang*,1 \\ ${ }^{1}$ Department of Surgery, University Hospital Regensburg, University of Regensburg Medical Center, Franz-Josef-Strauss Allee 11, \\ 93053 Regensburg, Germany and ${ }^{2}$ Department of Internal Medicine I, University Hospital Regensburg, University of Regensburg \\ Medical Center, Franz-Josef-Strauss Allee 11, 93053 Regensburg, Germany
}

Background: Systemic therapy has proven only marginal effects in hepatocellular carcinoma (HCC) so far. The aim of this study was to evaluate the effect of targeting fibroblast growth factor receptor (FGFR) on tumour and stromal cells in HCC models.

Methods: Human and murine HCC cells, endothelial cells (ECs), vascular smooth muscle cells (VSMCs), hepatic stellate cells (HSCs), human HCC samples, FGFR inhibitor BGJ398 and mammalian target of rapamycin (mTOR) inhibitor rapamycin were used. Effects on growth, motility, signalling and angiogenic markers were determined. In vivo subcutaneous and syngeneic orthotopic tumour models were used.

Results: In tumour cells and ECs, targeting FGFR showed significant inhibitory effects on signalling and motility. Minor effects of FGFR inhibition were observed on VSMCs and HSCs, which were significantly enhanced by combining FGFR and mTOR blockade. In vivo daily $\left(5 \mathrm{mg} \mathrm{kg}^{-1}\right)$ treatment with BGJ398 led to a significant growth inhibition in subcutaneous tumour models, but only a combination of FGFR and mTOR blockade impaired tumour growth in the orthotopic model. This was paralleled by reduced tumour cell proliferation, vascularisation, pericytes and increased apoptosis.

Conclusions: Targeting FGFR with BGJ398 affects tumour cells and ECs, whereas only a combination with mTOR inhibition impairs recruitment of VSMCs and HSCs. Therefore, this study provides evidence for combined FGFR/mTOR inhibition in HCC.

Liver cancer is the sixth most commonly diagnosed cancer worldwide, and hepatocellular carcinoma (HCC) accounts for the vast majority of cases (Jemal et al, 2011). Hepatocellular carcinoma almost exclusively develops upon chronic liver diseases such as viral hepatitis, alcohol abuse and nonalcoholic steatohepatitis. Surgery is the only curative treatment option, but owing to advanced stages and the underlying disease, few patients are eligible for surgical resection or liver transplantation (Bruix and Sherman, 2011). Therefore, novel therapeutic options are urgently needed.

So far, systemic therapy has been disappointing in HCC. Only the multityrosine kinase inhibitor sorafenib, acting via vascular endothelial growth factor-receptor (VEGF-R) and Raf kinases to inhibit angiogenesis, shows a modest benefit in clinical trials (Llovet et al, 2008). Nevertheless, therapies targeting high vascularisation, a common feature of HCC, remain promising (Zhu et al, 2011). In general, tumour angiogenesis is driven by certain factors such as VEGFs, platelet-derived growth factors (PDGFs) and fibroblast growth factors (FGFs) secreted from tumour and stromal cells (Zhu et al, 2011; Casazza et al, 2013). With HCC, high serum VEGF levels are associated with advanced or metastatic stages and poor survival after locoregional therapy (Yao et al, 2005; Poon et al, 2007). Furthermore, acidic FGF (aFGF, FGF-1) and basic FGF (bFGF, FGF-2) are involved in angiogenesis 
via effects on endothelial cell (EC) activation and recruitment (Lieu et al, 2011). In particular, increased levels of bFGF are detectable in HCC patients and the expression correlates with the microvessel density of the tumour and recurrence after resection (Poon et al, 2001; Harimoto et al, 2010). Therefore, angiogenesis is a crucial part of HCC development and progression.

The FGF/FGFR system consisting of four receptors (FGFR1-4) and 19 ligands (FGFs) is important for carcinogenesis. On a functional level, activation of intracellular cascades (MAPK/ERK or PI3K/Akt) upon ligand binding to FGFRs affects various cancer cell behaviours (Dieci et al, 2013). In particular, proliferation is mainly mediated via MAPK/ERK signalling, whereas cancer cell survival is affected by PI3K/Akt signalling. Moreover, tumour cell motility is at least, in part, influenced by both signalling pathways (Hu et al, 2013; Wang et al, 2013). In addition, activation of the FGF/FGFR system is associated with resistance after antiangiogenic therapy (Casanovas et al, 2005). Finally, the FGF/FGFR system has been implicated in recruitment of stromal cells, for example, ECs, which are important for HCC progression (Lieu et al, 2011). BGJ398 is a novel orally administered pan-FGFR kinase inhibitor under investigation in clinical phase I studies (Guagnano et al, 2011); this substance could offer an interesting antineoplastic approach for HCC treatment. Nonetheless, clinical studies with FGFR inhibitors have been disappointing so far. Therefore, we sought to assess alternative strategies beyond targeting 'only' FGFR. Activation of the mammalian target of rapamycin (mTOR) pathway has been associated with less differentiated tumours, bad prognosis and earlier recurrence in HCC (Matter et al, 2013). In particular, treatment with $\mathrm{mTOR}$ inhibitors such as rapamycin has demonstrated potent antineoplastic effects, at least in part, via targeting stromal cells in various preclinical cancer models including HCC (Huynh et al, 2009; Lang et al, 2009). Therefore, targeting the mTOR pathways provides an interesting therapeutic option for HCC.

Here, we hypothesised that inhibition of FGF/FGFR signalling impairs tumour growth in HCC models via effects on cancer and stromal cells. Our results demonstrate that targeting FGFR, particularly in combination with an mTOR inhibitor, is a new and promising strategy for the treatment of HCC.

\section{MATERIALS AND METHODS}

Reagents. Fibroblast growth factor receptor inhibitor BGJ398 (Novartis Oncology, Basel, Switzerland) was dissolved in dimethylsulphoxide (in vitro) and water (in vivo). Rapamycin (Wyeth, Madison, NJ, USA) was dissolved in water (in vivo) or cell culture medium (in vitro). Recombinant human bFGF was purchased from R\&D Systems (Wiesbaden, Germany). Antibodies against pAkt $^{\text {Ser473}}$, Akt, pERK ${ }^{\text {Tyr202/204 }}$, ERK, pFAK ${ }^{\text {Tyr397 }}$, FAK, pPaxillin ${ }^{\text {Tyr118, }}$, Paxillin, RhoA, E-cadherin, N-cadherin, c-myc (obtained from Cell Signaling, Beverly, MA, USA) and PDI (obtained from Santa Cruz Biotechnology, Santa Cruz, CA, USA) were used.

Cell culture. Human HCC lines (HepG2, Huh-7, Hep3B, PLC5; American Type Culture Collection, Manassas, VA, USA), human ECs and VSMCs as representatives for vascular pericytes (both Promocell, Heidelberg, Germany) were purchased. Murine Hepa129 cells were kindly provided by Prof. Volker Schmitz (University of Bonn, Bonn, Germany). Tumour cells, ECs, VSMCs and HSCs were processed as described (Amann et al, 2009; Lang et al, 2009); conditioned media (CM) were produced as published (Lang et al, 2009; Taeger et al, 2011).

Patient samples. Tumour specimens from 10 patients who underwent resection for HCC at the Department of Surgery, University Hospital Regensburg (Regensburg, Germany) were obtained. After resection, tumour samples were excised and immediately snap frozen. RNA was isolated using the RNeasy Mini Kit (Qiagen, Venlo, The Netherlands). The study was approved by the local ethics committee at the University of Regensburg (no. 12-101-0009). Informed consent was obtained before the surgical procedure.

Measurement of cell growth. To evaluate effects of targeting FGFR with BGJ398, tumour cells, ECs, VSMCs and HSCs were seeded into 96 -well plates $\left(1-2 \times 10^{3}\right.$ per well) for 24,48 and $72 \mathrm{~h}$ under complete medium and serum-starved conditions (10\% and $1 \%$ FCS in DMEM, respectively). Basic FGF $\left(50 \mathrm{ng} \mathrm{ml}^{-1}\right.$ ) was added to serum-starved conditions to assess effects on cell growth. MTT (3-(4,5-dimethylthiazol-2-yl)-2,5-diphenyltetrazolium) assay was used to assess cell growth. The effect of BGJ398 on tumour cell growth was also determined in a cell-counting assay (Taeger et al, 2011).

Cell motility. Migration assays were performed using modified Boyden chambers, as described (Lang et al, 2009). Briefly, $5 \times 10^{4}$ cells were resuspended in 1\% FCS-DMEM and seeded into $8 \mu \mathrm{m}$ filter pore inserts (BD, Heidelberg, Germany). Either FCS or bFGF $\left(50 \mathrm{ng} \mathrm{ml}^{-1}\right)$ served as a chemoattraction for cancer cells. In EC, VSMC and HSC, CM from HepG2 and Huh-7, as well as bFGF $\left(50 \mathrm{ng} \mathrm{ml}^{-1}\right)$, was used. Migrated cells were Wright-Giemsa stained and counted in four random fields.

Western blotting. Western blotting was performed as described previously (Lang et al, 2009). Briefly, whole-cell lysates were prepared and protein samples $(50 \mu \mathrm{g})$ were subjected to western blotting on a denaturating 10\% SDS-PAGE. Membranes were probed with indicated antibodies and detected by chemiluminescence (Amersham Bioscience, Piscataway, NJ, USA). To quantify results from western blotting, densitometry was performed using ImageJ (1.46r; http://imagej.nih.gov.ij). Expression of proteins was calculated in relation to the respective control (e.g. pAkt/Akt).

Measurement of VEGF-A, bFGF, PDGF-B, FGFRs and Tie2 mRNA. Total RNA was isolated, purified and $1 \mu \mathrm{g}$ aliquots of RNA were reverse transcribed. Primer pairs for PCR are shown as Supplementary Material. Reverse transcription-PCR was performed using the LightCycler system and Roche Fast-Start Light Cycler-Master Hybridisation Probes master mix (Roche, Mannheim, Germany). Hypoxia was chemically induced with desferroxamine (DFX; $100 \mathrm{nmoll}^{-1}$; Sigma, Taufkirchen, Germany) (Lang et al, 2007; Gauglhofer et al, 2011) and cells were incubated \pm BGJ398 $(100 \mathrm{nM})$ for the assessment of VEGF-A, bFGF, PDGF-B and Tie2.

Enzyme-linked immunosorbent assay for VEGF-A. To determine changes in VEGF-A secretion, we used an Enzyme-Linked Immunosorbent Assay (ELISA) Kit (BioSource, Nivelles, Belgium), as described (Lang et al, 2009). Hepatocellular carcinoma cells were plated at $40-50 \%$ density and incubated \pm BGJ398 and stimulated with DFX for $24 \mathrm{~h}$ before collection of culture supernatants.

Subcutaneous HCC models. Experiments were approved by the Institutional Animal Care and Use Committee of the University of Regensburg and the regional authorities. In addition, experiments were conducted according to 'Guidelines for the Welfare of Animals in Experimental Neoplasia' published by The United Kingdom Coordinating Committee on Cancer Research. Huh-7 cells $\left(1 \times 10^{6}\right)$ and Hepa129 cells $\left(2.5 \times 10^{5}\right)$ were subcutaneously injected into nude mice (Balb- $c_{n u / n u}, n=6-8$ mice per group) and $\mathrm{C} 3 \mathrm{H}$ mice ( $n=8-9$ mice per group) (Charles River, Sulzfeld, Germany), as described (Lang et al, 2009). Mice were randomised and assigned to control or treatment groups. Therapy was initiated when tumours reached a size of $\sim 100 \mathrm{~mm}^{3}$ with BGJ398 $\left(5 \mathrm{mg} \mathrm{kg}^{-1}\right.$ per day or $25 \mathrm{mg} \mathrm{kg}^{-1}$ per $3 \times$ per week) via oral gavage. Tumour diameters were measured and volumes calculated ( width $^{2} \times$ length $\times 0.5$ ). The experiment was terminated on day 
30 (Huh-7) or on day 14 (Hepa129). Tumours were excised and weighed.

Orthotopic tumour model. A total of $5 \times 10^{4}$ Hepa129 cells were injected into the left liver lobe of $\mathrm{C} 3 \mathrm{H}$ mice $(n=6-8$ mice per group), as described (Lang et al, 2009). Treatment was initiated on day 7 after tumour cell implantation, with the mice receiving: (1) BGJ398 $5 \mathrm{mg} \mathrm{kg}^{-1}$ per day (oral gavage), (2) rapamycin $0.2 \mathrm{mg} \mathrm{kg}^{-1}$ per day (intraperitoneally), (3) combination therapy or (4) water. Treatment was continued for 12 days. Mice were observed daily and killed when tumour-related symptoms occurred. Tumours were excised, measured and processed for immunohistochemistry at the end point (day 19).

Immunohistochemistry. Assessment of tumour cell proliferation and apoptosis was performed as described (Lang et al, 2009). To determine CD31-positive vessel area and intratumoral pericytes ( $\alpha$ SMA-positive cells), frozen tissue was fixed in cold acetone and chloroform, washed with PBS and exposed to primary antibodies against CD31 (1:50; Pharmingen, Heidelberg, Germany) or $\alpha$ SMA (1:50; Sigma), and respective secondary antibodies (Alexa Fluor 488 and $594 ; 1: 200)$.

Statistics. Statistics were performed using SigmaStat (Version 3.0, San Jose, CA, USA) and GraphPadPrism (Version 6.0, La Jolla, CA, USA). Results of in vivo experiments were analysed for significant outliers using Grubb's test (http://www.graphpad.com). Tumourassociated variables in in vivo experiments were tested for significance using the Mann-Whitney $U$-test and ANOVA test. The two-sided Student's $t$-test was applied for analysis of in vitro data. Results for migration assays and PCR are shown relative to control results. Expression of FGFRs in all HCC cell lines, stromal cells and patient samples is normalised to Hep3B as this tumour cell line expresses all FGFRs. All results were confirmed in independent experiments and are expressed as the mean \pm s.e.m.

\section{RESULTS}

Expression of FGFR1-4 in cancer cell lines, stromal cells and patient samples. To delineate the potential targets for BGJ398, we determined the expression of FGFRs in HCC cell lines, ECs, VSMCs, HSCs and 10 human HCC samples (named HCC1-10). Reverse transcription-PCR showed that all HCC cell lines (Huh-7, HepG2, Hep3B, PLC5) express FGFR1, FGFR3 and FGFR4. Fibroblast growth factor receptor 2IIIb was only found in Hep3B, which is in line with previously published results (Amann et al, 2010). Fibroblast growth factor receptor 2IIIc was detected in Hep3B and HepG2 cells and weakly in Huh-7 cells, but not in PLC5 cells (Figure 1A-E). Regarding stromal cells, no expression of FGFR2IIIb and FGFR2IIIc was found in VSMCs, ECs and HSCs, whereas FGFR1, FGFR3 and FGFR4 were detected in these cells. However, FGFR3 was only weakly expressed in HSCs and very little expression of FGFR4 was detectable in ECs (Figure 1A-E). Finally, assessment of tumour samples revealed a very heterogeneous picture. In general, all FGFRs were detectable in almost all 10 HCC samples that were used for these analyses (except FGFR1 in HCC5 and FGFR2IIIb in HCC1 and HCC7; Figure 1A-E). In conclusion, our results clearly demonstrate that FGFRs are expressed in HCC cell lines, stromal cells and also in human cancer specimens, and therefore might serve as a target for antiFGFR-directed therapy.

Effects of targeting FGFR with BGJ398 on tumour cells in vitro. Owing to the heterogeneous expression pattern of FGFRs in HCC cell lines, we initially used Huh-7 for the assessment of BGJ398 in vitro. Results were subsequently confirmed in HepG2, PLC5 and Hep3B, unless otherwise indicated. First, MTT assays showed significant growth inhibition by BGJ398 starting from $100 \mathrm{~nm}$ after $72 \mathrm{~h}$ (Figure $2 \mathrm{~A}$; $\mathrm{IC}_{50}(48 \mathrm{~h}): 2359 \mathrm{~nm}, \mathrm{IC}_{50}(72 \mathrm{~h})$ : $1124 \mathrm{~nm}$ ). After $48 \mathrm{~h}$, only the highest dose led to growth inhibition. Similar results were obtained for HepG2, PLC5 and Hep3B (Supplementary Figures 2A, 3A and 4A). Growth inhibitory effects
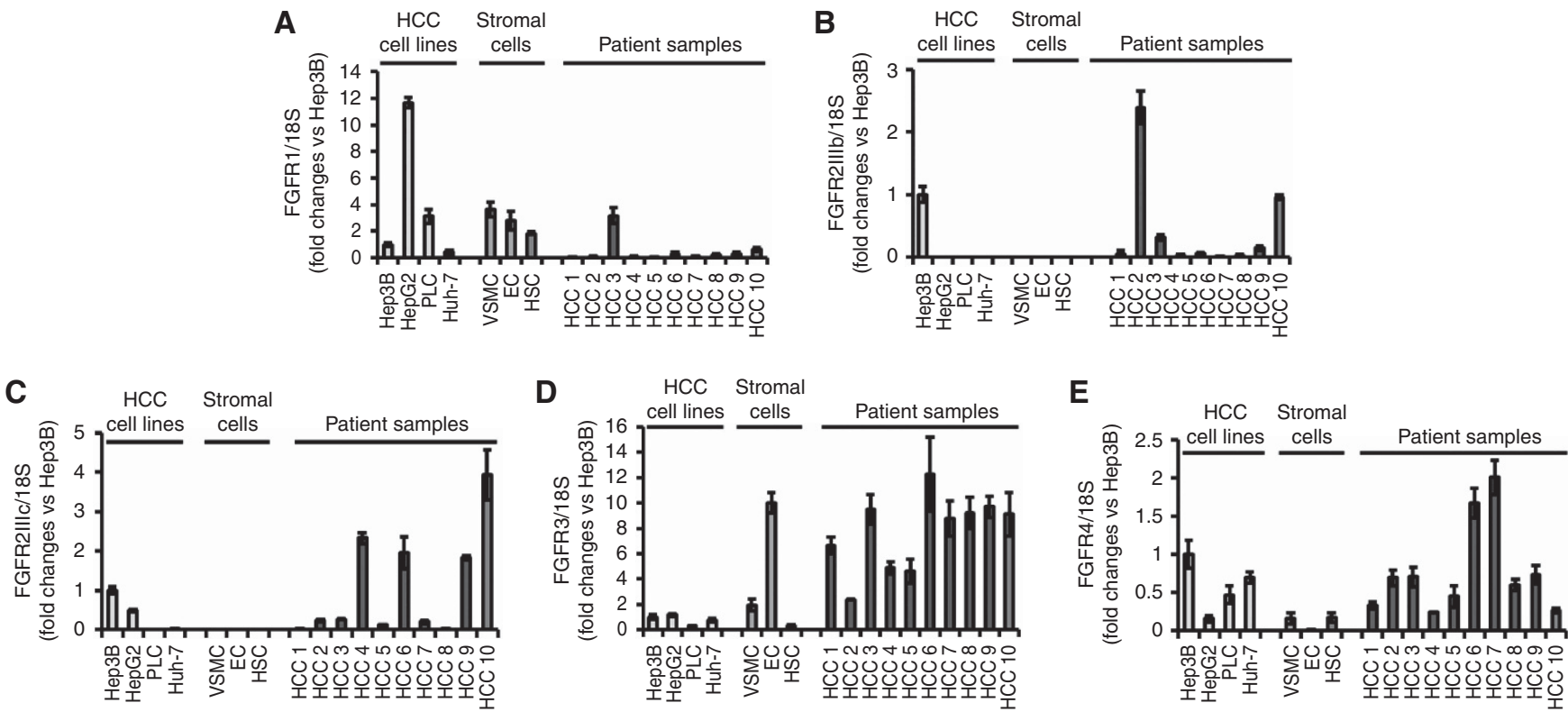

Figure 1. Expression of FGFRs in HCC cell lines, stromal cells and clinical samples. (A) Fibroblast growth factor receptor 1 expression was found in HCC cell lines, stromal cells and clinical samples. (B) Fibroblast growth factor receptor 2 Illb expression was only detected in Hep3B cells. Stromal cells did not express FGFR2IIlb, whereas all clinical samples except HCC1 did express various levels. (C) Fibroblast growth factor receptor 2lllc was observed in three HCC cell lines (very weak in Huh-7) and all clinical samples. No expression was found in stromal cells. (D) Fibroblast growth factor receptor 3 expression was detectable in all HCC cell lines, clinical samples and stromal cells. (E) Similar FGFR4 was found in all HCC cell lines, clinical samples and stromal cells, although expression in ECs was very weak. Bars=s.e.; results are normalised to Hep3B. 
A

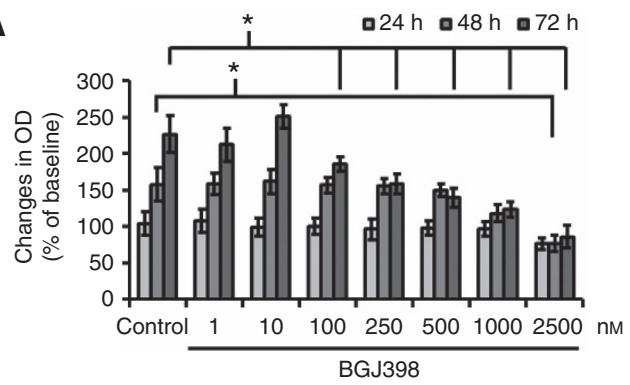

B $\square 24 \mathrm{~h} \square 48 \mathrm{~h} \quad \square 72 \mathrm{~h}$

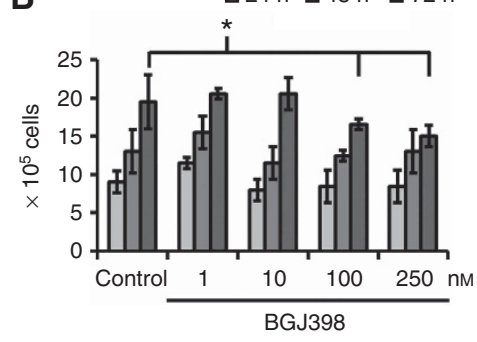

C

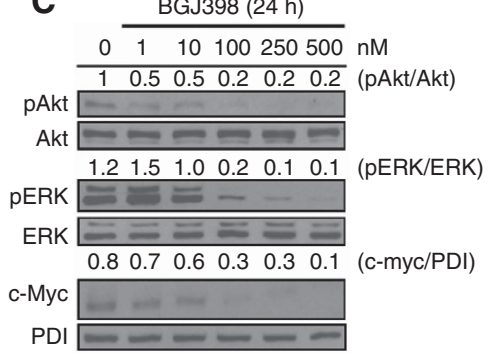

D

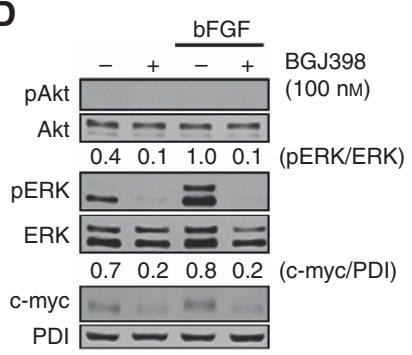

E

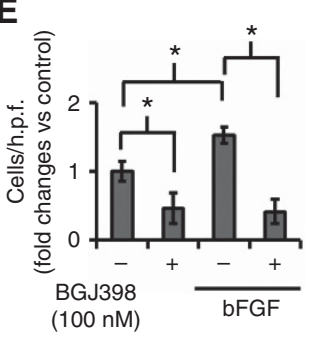

Figure 2. Effects of targeting FGFR with BGJ398 on cancer cells. (A) MTT assays showed impaired tumour cell growth after 48 and $72 \mathrm{~h}$ of treatment $\left({ }^{*} P<0.05\right)$. (B) Cell counting assays confirmed the MTT results ( $\left.{ }^{*} P<0.05\right)$. (C) Incubation with increasing doses of BGJ398 impaired phosphorylation of ERK, Akt and diminished expression of c-myc. (D) Basic FGF led to a marked induction of ERK phosphorylation, whereas Akt remains unaffected. BGJ398 impairs ERK in vitro. (E) BGJ398 significantly reduced constitutive and bFGF-induced migration (* $P<0.05$ ).

were subsequently confirmed for Huh-7 in cell count assays (Figure 2B). Analyses of signalling intermediates by western blotting after $24 \mathrm{~h}$ of incubation with increasing doses of BGJ398 showed a dose-dependent inhibition of constitutive Akt, ERK phosphorylation and c-myc expression in Huh-7 (Figure 2C). Effects on ERK signalling and c-myc expression after $24 \mathrm{~h}$ were confirmed in HepG2, PLC5 and Hep3B, whereas constitutive Akt phosphorylation was not detectable in these cell lines (data not shown). Furthermore, incubation of cancer cell lines with BGJ398 led to the inhibition of bFGF-induced ERK phosphorylation (Figure 2D). Surprisingly, Akt phosphorylation was not increased upon bFGF incubation. This was confirmed in HepG2, PLC5 and Hep3B (Supplementary Figures 2B, 3B and 4B). Migration assays showed a significant reduction of constitutive and bFGF-induced tumour cell motility after $24 \mathrm{~h}$ by BGJ398 in all HCC cell line (Figure 2E, Supplementary Figures 1A, 2C, 3C and 4C), whereas effects on constitutive migration were only found in Huh-7 and Hep3B (Supplementary Figures 2C, 3C and 4C). In summary, results so far indicate that FGFR inhibition has minor effects on growth of cancer cells, but substantially impairs oncogenic signalling and tumour cell motility in vitro.

Modulation of angiogenic factors by FGFR inhibition. As angiogenesis has a crucial role in HCC, we next assessed the expression of angiogenic factors upon FGFR inhibition in HCC cell lines. Results showed a significant reduction of DFX-induced PDGF-B and VEGF-A mRNA expression upon FGFR inhibition in all HCC cell lines cells (Figure $3 \mathrm{~A}$ and $\mathrm{B}$ and Supplementary Figures 2D, 2E, 3D, 3E, 4D and 4E). Enzyme-linked immunosorbent assay confirmed the significant reduction of DFX-induced VEGF-A secretion when cells were incubated for $24 \mathrm{~h}$ with BGJ398 (Figure 3C and Supplementary Figures 2F, 3F and 4F). However, bFGF mRNA expression was significantly reduced in HepG2, PLC5 and Hep3B cells after BGJ398 treatment, whereas Huh-7 cells showed no significant response (Figure 3D and Supplementary Figures 2G, 3G and 4G). Nonetheless, these results indicate that FGFR inhibition with BGJ398 has the potential to reduce the expression of angiogenic factors in HCC cell lines in vitro.
Effects of FGFR inhibition on ECs in vitro. Endothelial cells are essential for tumour growth and angiogenesis. MTT assays with BGJ398 showed significant growth inhibition after $72 \mathrm{~h}$ incubation with BGJ398 starting with $100 \mathrm{~nm}$ (Supplementary Figure 5A; $\mathrm{IC}_{50}$ $(72 \mathrm{~h})>2500 \mathrm{~nm})$. Incubation with bFGF did not have an effect on growth in vitro (Supplementary Figure 5B). Western blotting revealed a dose-dependent inhibition of constitutive ERK phosphorylation, but no apparent impact on Akt phosphorylation after $24 \mathrm{~h}$ of BGJ398 treatment (Supplementary Figure 5C). Migration assays exhibited a significant reduction in constitutive and bFGFinduced EC motility upon BGJ398 addition (Figure 4A). Furthermore, bFGF-induced ERK, Akt phosphorylation and constitutive c-myc expression was diminished by BGJ398 (Figure 4B). To further analyse the effects of the local microenvironment on recruitment of ECs, CM from Huh-7 and HepG2 cells was used. We chose CM from these two cell lines because of their different response to FGFR inhibition with regard to bFGF mRNA expression (Figure 3D and Supplementary Figure 2G); a previous report indicates that reduced expression of FGFR2IIIb confers more aggressive growth in HCC, and both cell lines do not express this molecule (Amann et al, 2010). Migration assays revealed an induction of motility that was partially impaired by targeting FGFR (Figure 4C for CM from Huh-7 and Supplementary Figure 5D for CM from HepG2). Regarding angiogenic factors, RT-PCR showed no changes in PDGF-B or bFGF mRNA expression, even upon DFX induction (data not shown); only constitutive VEGF-A expression was reduced (Supplementary Figure 5E). Finally, Tie2 mRNA was reduced upon FGFR blockade, particularly when cells were stimulated with hypoxia-mimicking DFX (Figure 4D). In summary, ECs are susceptible to FGFR inhibition with BGJ398, especially when stimulated with bFGF or conditioned media from HCC cell lines.

Targeting FGFR in VSMCs in vitro. Vascular smooth muscle cells are essential for functional vascular system development in tumours. MTT assays did not show any significant effects on VSMC growth by targeting FGFR with BGJ398 (Supplementary Figure 6A), which was also confirmed when cells were stimulated 

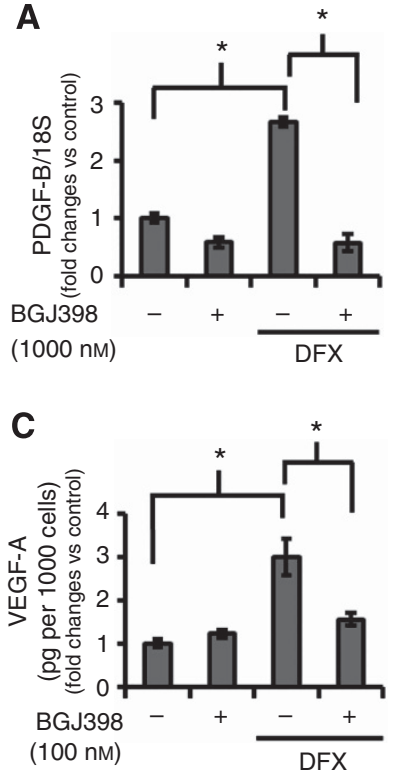

B

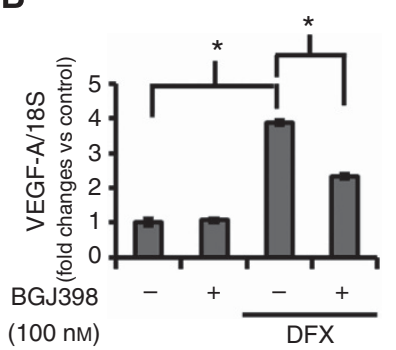

D

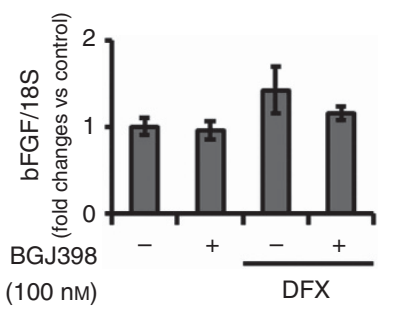

Figure 3. Modulation of angiogenic markers in cancer cells by FGFR blockade. (A) Fibroblast growth factor receptor inhibition reduces DFXinduced PDGF-B mRNA expression ( ${ }^{\star} P<0.05$ ). (B) Fibroblast growth factor receptor inhibition leads to impairment of constitutive and DFXinduced VEGF-A mRNA expression ( $\left.{ }^{\star} P<0.05\right)$. (C) Similar treatment with BGJ398 significantly impairs DFX-induced VEGF-A secretion, as determined by ELISA ( $\left.{ }^{*} P<0.05\right)$. (D) Fibroblast growth factor receptor inhibition has no effect on bFGF mRNA expression. Bars =s.e.m. Results are shown for Huh-7.

with bFGF (data not shown). Similarly, constitutive and bFGFinduced migration was unaffected by BGJ398 (Figure 4E). However, constitutive ERK phosphorylation and c-myc expression was diminished after $24 \mathrm{~h}$ incubation with BGJ398 (Supplementary Figure 6B). Moreover, incubation with bFGF strongly induced ERK phosphorylation, which was impaired by BGJ398 (Figure 4F). Interestingly, CM from Huh-7 and HepG2 cells strongly induced VSMC migration, which, however, was unaffected by FGFR inhibition (Figure 4G for CM from Huh-7 and Supplementary Figure 6C for CM from HepG2). Finally, FGFR blockade had no effect on DFX-induced VEGF-A expression (Supplementary Figure 6D). Moreover, FGFR inhibition significantly increased bFGF mRNA expression (Supplementary Figure 6E), whereas no PDGF-B mRNA expression of was detectable in VSMCs (data not shown). Taken together, these results emphasise that targeting FGFR has only minor effects on recruitment and expression of angiogenic factors in VSMCs in vitro.

FGFR blockade in HSCs in vitro. Liver-specific pericytes (HSCs) affect the development and progression of liver malignancies and therefore were studied (Yin et al, 2013). Growth inhibition by FGFR blockade on HSCs were found after $72 \mathrm{~h}$ in MTT assays, especially upon bFGF stimulation (Figure $5 \mathrm{~A} ; \mathrm{IC}_{50}(72 \mathrm{~h})$ upon constitutive conditions: $>2500 \mathrm{~nm}$; $\mathrm{IC}_{50}(72 \mathrm{~h})$ upon bFGF stimulation: $462 \mathrm{~nm}$ ). Migration assays revealed no induction by bFGF, and BGJ398 had no significant effect on HSC motility (Figure 5B). Assessment of signalling pathways showed a marginal inhibition of constitutive ERK phosphorylation and c-myc expression, whereas no effect on Akt phosphorylation was observed (Supplementary Figure 7A). However, stimulation of HSCs with bFGF led to ERK and Akt phosphorylation that was
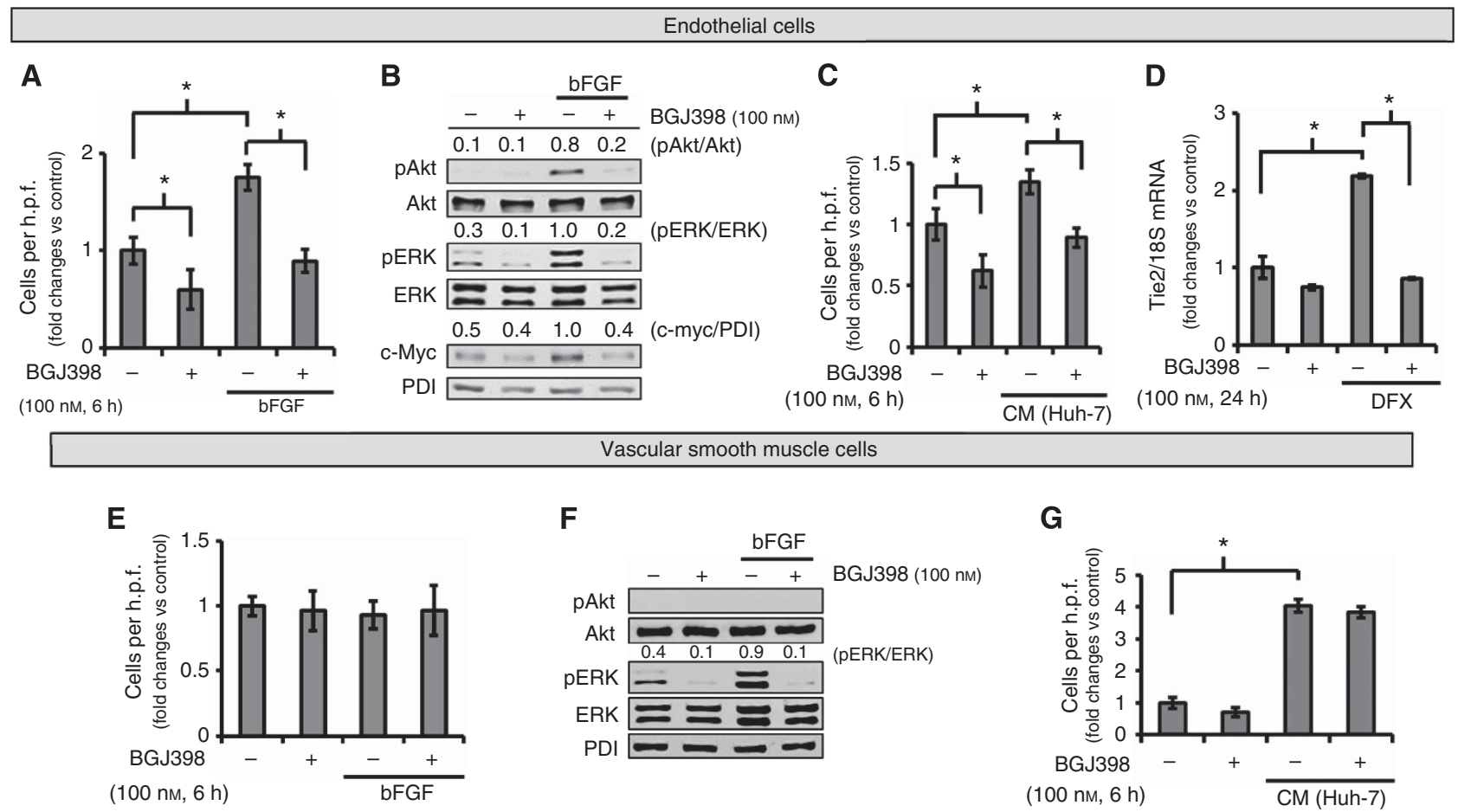

Figure 4. Inhibition of FGFR in ECs and VSMCs. (A) Basic FGF induces EC motility. Fibroblast growth factor receptor blockade impairs constitutive and bFGF-driven migration ( ${ }^{*} P<0.05$ ). (B) Marked reduction of bFGF-induced ERK and Akt phosphorylation and constitutive c-myc expression by FGFR blockade in ECs. (C) After 6 h, FGFR inhibition led to a significant reduction in constitutive and conditioned medium (CM)-induced EC motility $\left({ }^{\star} P<0.05\right)$. (D) Hypoxia-mimicking DFX strongly induces Tie2 expression. This can be significantly reduced by FGFR inhibition $\left({ }^{\star} P<0.05\right)$. (E) Basic FGF had no effects on VSMC motility in vitro. (F) Nonetheless, treatment with BGJ398 abrogated bFGF-induced ERK phosphorylation in VSMCs. (G) Although CM from HCC cell lines strongly induced VSMC motility, no effects were observed by FGFR blockade (* $P<0.05$ ).

Bars $=$ s.e.m. 
A

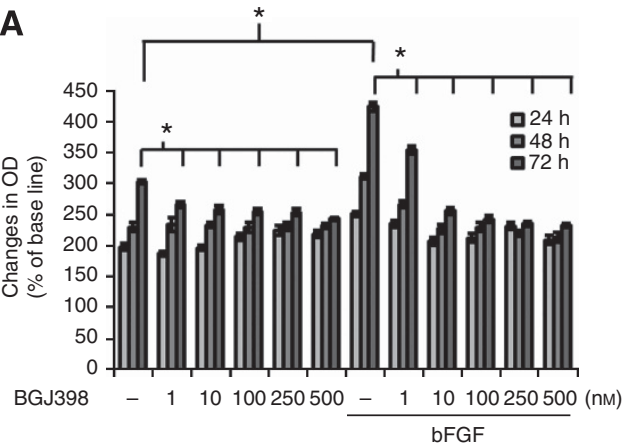

C

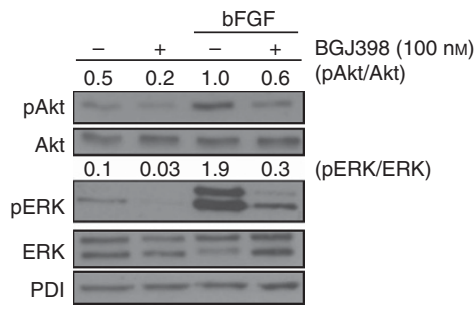

B
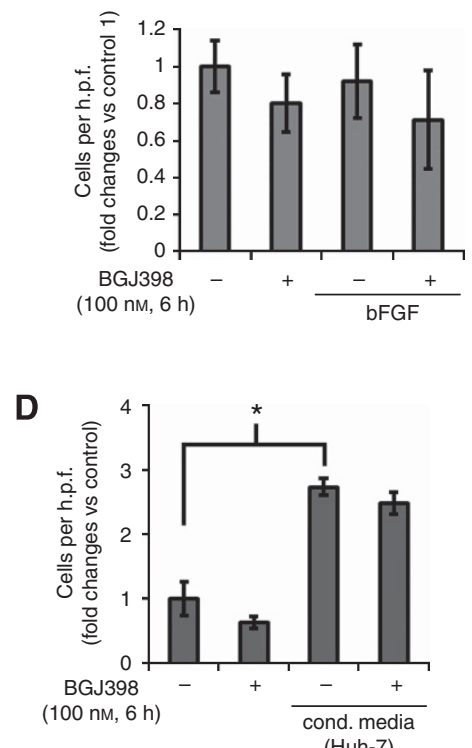

Figure 5. Targeting FGFR in HSCs. (A) Fibroblast growth factor receptor inhibition with BGJ398 leads to growth inhibition after $72 \mathrm{~h}\left({ }^{\star} P<0.05\right)$. Incubation with bFGF induces HSC growth, which can be abrogated by FGFR blockade ( $P<0.05)$. (B) BGJ398 had no impact on constitutive and bFGF-induced HSC motility in vitro. (C) Basic FGF led to induction of Akt and ERK phosphorylation, which was markedly reduced by BGJ398.

(D) Conditioned medium (CM) from human HCC cell lines induces HSC motility, although no effect was observed by FGFR blockade ( ${ }^{\star}<<0.05$ ).

markedly inhibited by BGJ398 (Figure 5C). To determine the recruitment of HSCs to HCC-specific sites, migration assays with CM from Huh-7 and HepG2 cells were performed. Results indicated no alterations of CM-induced HSC motility by FGFR blockade (Figure 5D and Supplementary Figure 7B). Finally, VEGF-A mRNA expression was not affected by FGFR blockade even upon stimulation with DFX (Supplementary Figure 7C). Interestingly, expression of PDGF-B mRNA was induced upon treatment with BGJ398. However, these results were conflicting as DFX led to a slight reduction of PDGF-B mRNA in HSCs (data not shown). Furthermore, expression of bFGF mRNA was not detectable in HSCs in vitro (data not shown). Taken together, results from these experiments indicate that targeting FGFR has an effect on growth and signalling, but not on recruitment of HSCs in vitro.

Modulation of tumour growth in subcutaneous models. Next, we assessed FGFR blockade with BGJ398 in vivo using a xenogeneic subcutaneous tumour model (Huh-7). We chose a low-dose $\left(5 \mathrm{mg} \mathrm{kg}^{-1}\right.$ per day) and a bolus application $\left(25 \mathrm{mg} \mathrm{kg}^{-1}\right.$ $3 \times$ per week) schedule. Results showed a significant inhibition of tumour growth as reflected by tumour volume and tumour weight upon either daily $\left(5 \mathrm{mg} \mathrm{kg}^{-1}\right)$ or $3 \times$ weekly $\left(25 \mathrm{mg} \mathrm{kg}^{-1}\right)$ treatment schedules (Figure $6 \mathrm{~A}$ and $\mathrm{B}$ ). Nevertheless, the daily treatment tended to be more effective than the higher, less frequent, dosing schedule. This was subsequently confirmed in a subcutaneous syngeneic tumour model (Hepa129) showing again growth inhibition by daily $\left(5 \mathrm{mg} \mathrm{kg}^{-1}\right)$ treatment (Figure $6 \mathrm{C}$ and D). However, efficacy of FGFR blockade in the syngeneic model was less impressive than in the xenogeneic model. Nonetheless, data from these experiments indicate that low-dose FGFR inhibition with BGJ398 is an effective therapy in HCC models in vivo.

Combination of FGFR inhibition with mTOR blockade in vitro. Results from our experiments, so far, show that FGFR blockade with BGJ398 is effective against tumour cells and ECs, whereas VSMCs and HSCs are less affected. To further improve antitumour activity of FGFR inhibition, we sought to combine
BGJ398 with a pericyte-targeting agent. From previous studies, we know that mTOR blockade impairs recruitment of pericytes, in particular VSMCs (Lang et al, 2009). Therefore, we assessed a combination of targeting FGFR with mTOR inhibition using rapamycin. In vitro experiments with HSCs showed an impairment of HSC growth upon combination of FGFR and mTOR inhibition (Figure 7A). Interestingly, treatment with rapamycin led to Akt phosphorylation and a slight increase in c-myc expression that was not affected by BGJ398 in HSCs (Figure 7B). Moreover, motility of HSCs was significantly reduced when FGFR inhibition was combined with mTOR blockade (Figure 7C and D). To further delineate the latter effect, we assessed other pathways that are involved in cell motility. Results showed no effect on FAK, RhoA, $\mathrm{E}$-cadherin or $\mathrm{N}$-cadherin. Of note, rapamycin led to an increase in paxillin expression (total and phosphorylated), which was reduced by a combination treatment with FGFR inhibition (Figure 7E). Nonetheless, these results did not explain the reduction in HSC motility and therefore warrant further exploration. However, our results clearly show that addition of the mTOR inhibitor rapamycin improved the efficacy of targeting FGFR in HSCs in vitro.

Finally, we used Huh-7 for comparative experiments with FGFR/mTOR blockade. In line with previous results from our group, we observed an induction of Akt phosphorylation upon rapamycin treatment (Lang et al, 2009). However, in contrast to HSCs, this phosphorylation was impaired upon combined treatment with the FGFR inhibitor BGJ398 (Supplementary Figure 8A). In addition, a significant reduction of in vitro growth in MTT assays was found upon FGFR/mTOR blockade (Supplementary Figure 8B). The latter was also confirmed in all other HCC cell lines used in the study (data not shown). In conclusion, our results demonstrate that combination of FGFR inhibition with mTOR blockade improves the efficacy of single-agent treatment also in cancer cells.

Combined FGFR/mTOR blockade in the orthotopic tumour model. As the local microenvironment is essential for tumour growth, we finally evaluated the effects of FGFR blockade in 

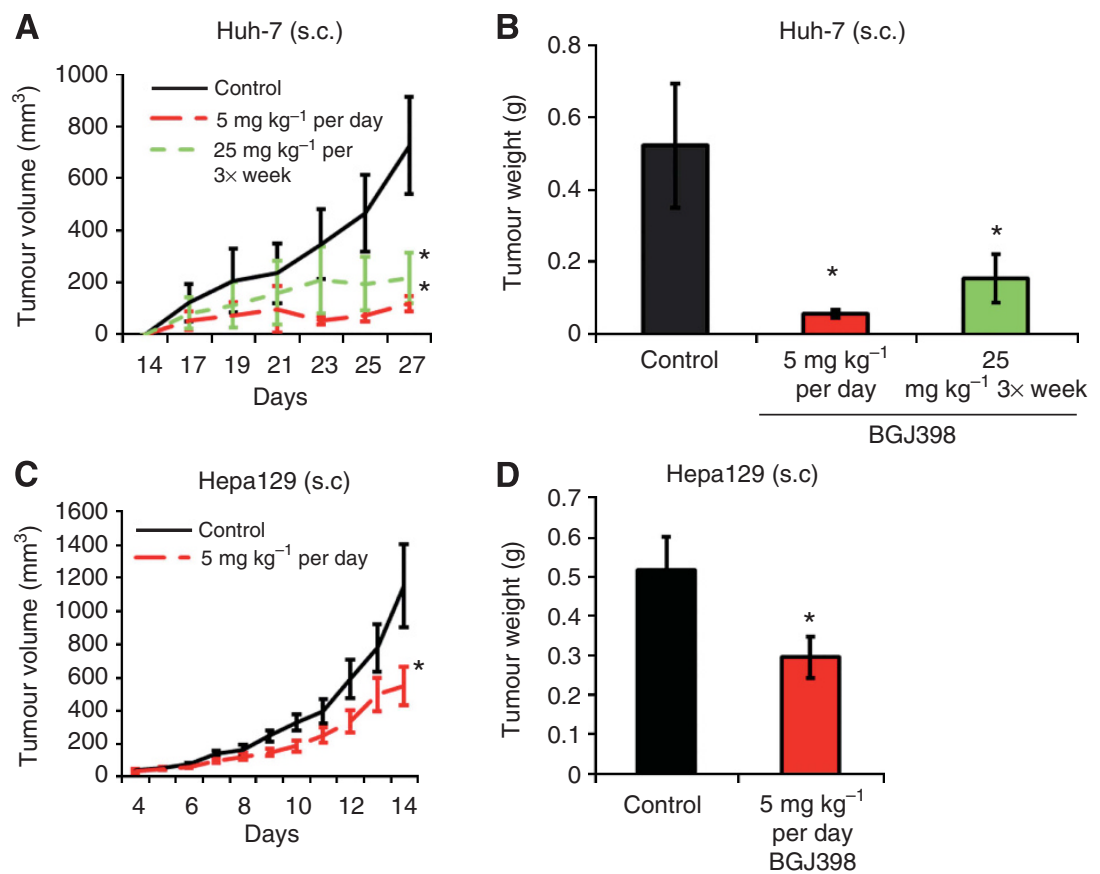

Figure 6. Subcutaneous (s.c.) tumour model. (A) In the subcutaneous xenograft model (Huh-7) treatment with FGFR inhibitor BGJ398 showed an inhibition of tumour growth upon both treatment schedules, $5 \mathrm{mg} \mathrm{kg}^{-1}$ per day and $25 \mathrm{mg} \mathrm{kg}^{-1}$ three times weekly ( $n=6-8$ mice per group; $\left.{ }^{\star} P<0.05\right)$. (B) This was also reflected by final tumour weight $\left({ }^{*} P<0.05\right)$. (C) Similarly, the subcutaneous syngenic tumour model (Hepa129) confirmed significant growth inhibition upon daily treatment $\left(5 \mathrm{mg} \mathrm{kg}^{-1}\right.$ per day) $\left(n=8-9\right.$ mice per group; $\left.{ }^{*} P<0.05\right)$. (D) Final tumour weight in the subcutaneous syngeneic model $\left({ }^{\star} P<0.05\right)$.

A

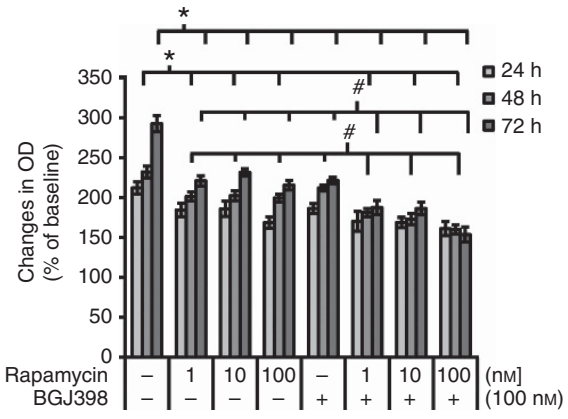

C

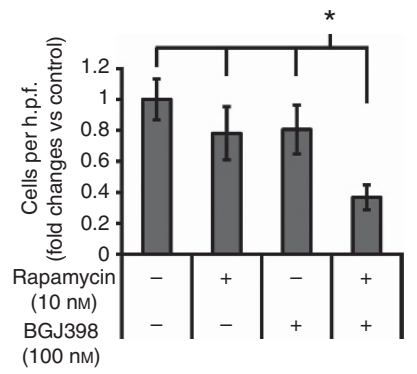

D

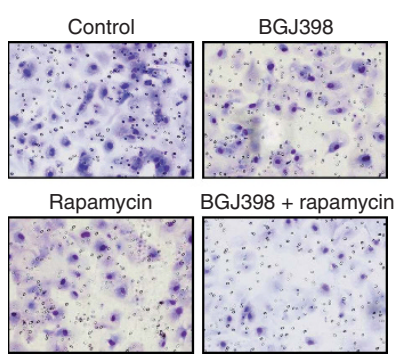

B

BGJ398

$(100 \mathrm{nM} ; 24 \mathrm{~h})$

Rapamycin $0 \quad 1 \quad 10100 \overline{0} 110100$ (nM)

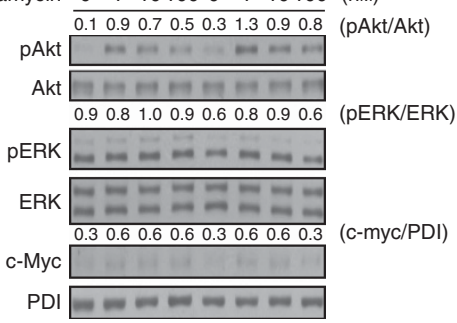

E

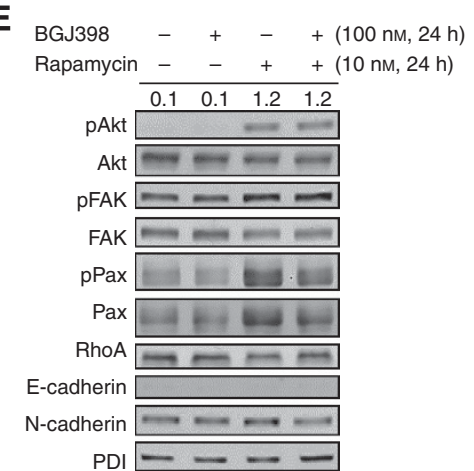

Figure 7. Combination of FGFR and mTOR blockade in HSCs. (A) Combination of FGFR inhibition with mTOR blockade impairs growth of HSCs in vitro compared with control $\left({ }^{\star} P<0.05\right)$ and vs single agents $\left({ }^{\#} P<0.05\right)$. (B) Twenty four hours of treatment with rapamycin leads to induction of Akt phosphorylation in HSCs. Fibroblast growth factor receptor inhibition has no effect on this induction. (C) Combination of FGFR and mTOR inhibition significantly impairs HSC motility in vitro ( $\left.{ }^{*}<<0.05\right)$. (D) Examples for HSCs from migration assays. (E) Incubation with rapamycin leads to induction of Akt phosphorylation in HSCs. No other pathways involved in cell motility were affected.

combination with mTOR inhibition on HCC growth in a syngeneic orthotopic tumour model (Hepa129). Based on our previous experiments, we decided to combine the daily treatment of BGJ398 $\left(5 \mathrm{mg} \mathrm{kg}^{-1}\right)$ with low-dose rapamycin $\left(0.2 \mathrm{mg} \mathrm{kg}^{-1}\right.$ per day). Results showed only minor inhibition of tumour growth (nonsignificant) upon treatment with either BGJ398 or rapamycin 

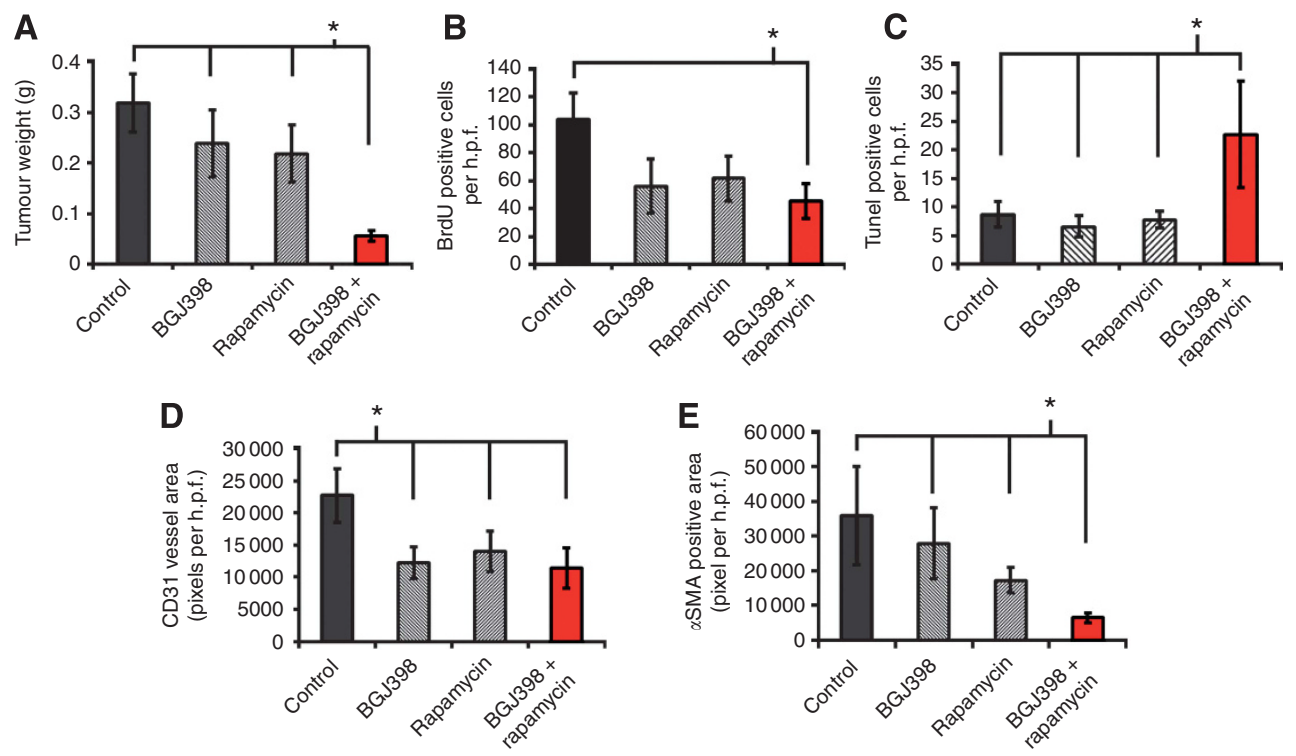

$\mathbf{F}$
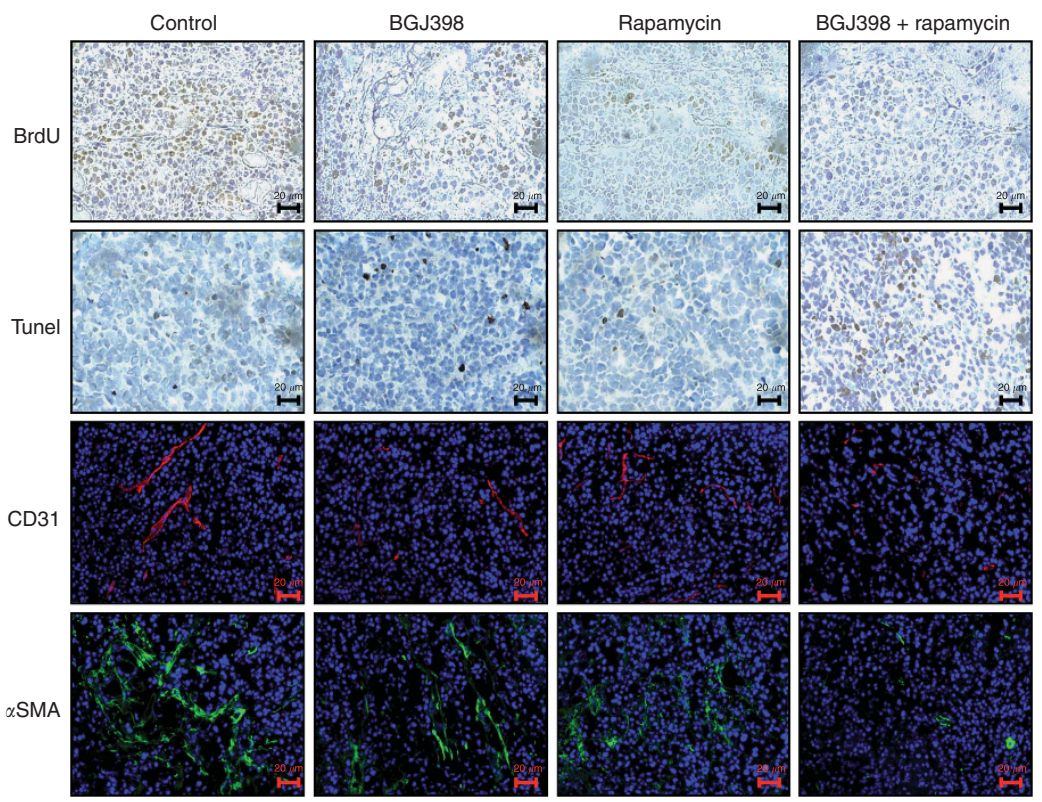

Figure 8. Syngeneic orthotopic HCC model. (A) Slight, but not significant, inhibition of tumour growth upon treatment with either BGJ398 ( $5 \mathrm{mg} \mathrm{kg}^{-1}$ per day) or rapamycin $\left(0.2 \mathrm{mg} \mathrm{kg}^{-1}\right.$ per day) was observed. Combination of BGJ398 and rapamycin led to a significantly reduced final tumour weight. ( $n=6-8$ mice per group). (B) Proliferating cells were significantly diminished upon combination of FGFR and mTOR inhibition. (C) Tumour cell apoptosis was strongly induced in the combined treatment group. (D) Vascularisation was impaired upon single-agent and combination therapy. (E) Pericytes were significantly reduced in the combination group but not upon single-agent therapy. (F) Examples for BrdU, Tunel, CD31 and $\alpha$ SMA staining $\left({ }^{\star} P<0.05\right)$. Bars $=$ s.e.m.

alone, whereas the combination of both agents was very effective in terms of reduced tumour weight (Figure 8A). No difference regarding animal weight between the groups was observed (data not shown). Immunohistochemical workup revealed an inhibition of tumour cell proliferation (Figure $8 \mathrm{~B}$ and $\mathrm{F}$ ) and an induction of tumour cell apoptosis that reached significance only upon combination of FGFR/mTOR blockade (Figure 8C and F). Furthermore, assessment of tumour vascularisation with CD31 staining showed reduced blood vessel area in all treatment groups, indicating no further enhanced antiangiogenic effect by combining FGFR and mTOR blockade (Figure 8D and F). Finally, $\alpha$ SMA, a marker for VSMCs and HSCs, was strongly reduced in tumours treated with rapamycin and BGJ398 (Figure 8E and F). In conclusion, combined targeting of FGFR and mTOR impairs HCC tumour growth via effects on tumour cells and HSCs/VSMCs in vivo.

\section{DISCUSSION}

The FGF/FGFR system is of particular importance for tumour growth in human cancer (reviewed in Dieci et al, 2013). With regard to HCC, Gauglhofer et al (2011) showed that at least one member of the FGF8 subfamily and/or the corresponding receptors (FGFR2-4) is overexpressed in $\sim 80 \%$ of HCC samples. Finn et al (2012) published a phase II study with brivanib, a VEGFR/FGFR inhibitor, showing promising results in patients pretreated with sorafenib. Although the follow-up phase III study failed its primary end point of overall survival, the substance showed some activity regarding time-to-progression, disease control rate and objective response rate (Llovet et al, 2012). Therefore, the concept of targeting FGFR remains under investigation. In our study, almost all FGFRs were expressed in 10 HCC samples. In contrast, both 
isoforms of FGFR2 (IIIb and IIIc) were not detectable in stromal cells and most HCC cell lines (except for Hep3B). However, the meaning of FGFR2 in HCC remains controversial. Amann et al (2010) showed that reduced expression of FGFR2IIIb mediates a more aggressive behaviour of HCCs, whereas Harimoto et al (2010) found an association of FGFR2 expression with poor differentiation and poor survival in patients with HCC, although this study did not distinguish between the two isoforms of FGFR2. Nonetheless, in vitro experiments with HCC cell lines and ECs revealed that treatment with the FGFR inhibitor BGJ398 impaired oncogenic signalling and motility in HCC cell lines and ECs. Interestingly, HSCs and VSMCs that show a similar FGFR expression pattern as ECs respond differently to FGFR inhibition with regard to motility upon incubation with $\mathrm{CM}$ from cancer cells. These results suggest that recruitment of HSCs and VSMCs to HCC sites is dependent on factors other than FGFs such as PDGF-B (Kastanis et al, 2011; Azahri et al, 2012). Finally, we recognised that single-agent therapy with the FGFR inhibitor BGJ398 is most effective when the substance is used on a daily lowdose (metronomic) schedule. From the in vivo results, one can assume that no further improvement of antitumour activity is likely to be obtained by using higher doses of FGFR inhibitors in HCC therapy. This might be one of the reasons for the failure of the clinical trials with FGFR inhibitor. Nonetheless, results from our study further support the concept of targeting FGFR in HCC.

Angiogenesis is a hallmark of HCC development and progression and antiangiogenic therapy has shown some efficacy (Llovet et al, 2008). In this respect, results from our study show that VEGF-A and PDGF-B are reduced in cancer cells after FGFR inhibitor treatment. In addition, we found c-myc expression to be impaired in all cell types in vitro upon FGFR blockade. As c-myc is a major driver of tumour angiogenesis (Chen et al, 2013) and its expression has been associated with HCC recurrence (Cui et al, 2004), this is an important finding. Furthermore, FGFR inhibition in ECs led to reduced constitutive VEGF-A and, more interesting, Tie2 expression. As Tie2 encodes for the corresponding receptor for angiopoietin-2 (involved in resistance to antiangiogenic therapy (Daly et al, 2013), one can deduce that treatment with BGJ398 impairs mechanisms involved in resistance to antiangiogenesis. To our knowledge, this is the first time that Tie2 expression has been linked to FGFR, although this finding warrants further evaluation. Nonetheless, treatment with BGJ398 led to impairment of ECs recruitment, which is a supportive evidence for the antiangiogenic properties of this agent. We conclude that FGFR inhibition impairs tumour angiogenesis and potentially prevents resistance to antiangiogenic therapies.

Stromal cells and the local microenvironment are of particular importance for tumour growth in HCC (Hernandez-Gea et al, 2013). As our study showed only modest effects of FGFR inhibition with BGJ398 on recruitment of VSMCs and HSCs, pericytes are obviously left relatively unaffected by only FGFR blockade. To address this therapeutic gap, we combined BGJ398 treatment with the mTOR inhibitor rapamycin. This approach was based on our previous findings that VSMC recruitment is impaired upon mTOR blockade (Lang et al, 2009), and additional results with HSCs indicating a similar enhanced effect of combined FGFR/mTOR inhibition. Interestingly, treatment with rapamycin led to an induction of Akt phosphorylation in cancer cells and HSCs, even though our previous results have shown that mTOR inhibition does not affect Akt phosphorylation in ECs and VSMCs (Lang et al, 2009). The induction of Akt phosphorylation in cancer cells has been described by others and us before. In particular, phosphorylation at Ser473 has been linked to the IGF-IR/IRS-1 system (Wan et al, 2007; Lang et al, 2010) and the mTORC2 complex (Sarbassov et al, 2005). Therefore, it remains unexpected that treatment with an FGFR inhibitor impairs mTOR inhibitormediated Akt phosphorylation in cancer cells. Guagnano et al (2011) found a specificity of BGJ398 for FGFR, but neither the IGF-IR system nor mTORC2 was assessed in their work. Thus, an off-target effect might explain the observed inhibition rapamycininduced Akt phosphorylation. More interestingly, HSCs obviously show different regulation of Akt phosphorylation as FGFR inhibition did not affect the activation of Akt in these cells. From our data, we cannot explain this, and, therefore, differences in the response of HSCs to mTOR inhibition compared with cancer cells clearly warrant further exploration.

Finally, combination of FGFR inhibition with mTOR blockade in the orthotopic model demonstrated an enhanced effect, whereas either agent alone was not effective. These results also strongly emphasise the importance of addressing the local microenvironment by using syngeneic orthotopic models to assess new therapeutic strategies (Talmadge et al, 2007; Hernandez-Gea et al, 2013). Moreover, reduced expression of $\alpha \mathrm{SMA}$, a marker for pericytes (VSMCs, HSCs), in the combination group further supports our hypothesis that mTOR inhibition adds substantial benefit to FGFR inhibition via pericyte targeting. We speculate that FGFR inhibitors lack of efficacy on pericyte recruitment is a reason for the failure of clinical studies using these agents against HCC. In conclusion, our study provides evidence that the efficacy of FGFR inhibitors in HCC can be enhanced by adding pericyte-targeting agents such as rapamycin. Therefore, targeting FGFR/mTOR represents a novel and promising alternative strategy in the treatment of HCC.

\section{ACKNOWLEDGEMENTS}

We thank Christine Wagner and Julia Redekopf for excellent technical assistance. This study was supported by the German Research Foundation (LA1988/2-1; LA1988/3-1; LA1988/4-1) to SAL and CH (HE2458/14-1; HE 2458/15-1) and the Else-Kröner Fresenius Foundation (EKFS) to SAL.

\section{CONFLICT OF INTEREST}

The authors declare no conflict of interest.

\section{REFERENCES}

Amann T, Bataille F, Spruss T, Dettmer K, Wild P, Liedtke C, Muhlbauer M, Kiefer P, Oefner PJ, Trautwein C, Bosserhoff AK, Hellerbrand C (2010) Reduced expression of fibroblast growth factor receptor $2 \mathrm{III}$ in hepatocellular carcinoma induces a more aggressive growth. Am J Pathol 176(3): 1433-1442.

Amann T, Bataille F, Spruss T, Muhlbauer M, Gabele E, Scholmerich J, Kiefer P, Bosserhoff AK, Hellerbrand C (2009) Activated hepatic stellate cells promote tumorigenicity of hepatocellular carcinoma. Cancer Sci 100(4): 646-653.

Azahri NS, Di Bartolo BA, Khachigian LM, Kavurma MM (2012) Sp1, acetylated histone- 3 and p300 regulate TRAIL transcription: mechanisms of PDGF-BB-mediated VSMC proliferation and migration. J Cell Biochem 113(8): 2597-2606.

Bruix J, Sherman M (2011) Management of hepatocellular carcinoma: an update. Hepatology 53(3): 1020-1022.

Casanovas O, Hicklin DJ, Bergers G, Hanahan D (2005) Drug resistance by evasion of antiangiogenic targeting of VEGF signaling in late-stage pancreatic islet tumors. Cancer Cell 8(4): 299-309.

Casazza A, Di Conza G, Wenes M, Finisguerra V, Deschoemaeker S, Mazzone M (2013) Tumor stroma: a complexity dictated by the hypoxic tumor microenvironment. Oncogene 33(14): 1743-1754.

Chen C, Cai SX, Wang GH, Cao XN, Yang X, Luo XL, Feng YD, Hu JB (2013) c-Myc enhances colon cancer cell-mediated angiogenesis through the regulation of HIF-1 alpha. Biochem Biophys Res Commun 430(2): 505-511. 
Cui J, Dong BW, Liang P, Yu XL, Yu DJ (2004) Effect of c-myc, Ki-67, MMP-2 and VEGF expression on prognosis of hepatocellular carcinoma patients undergoing tumor resection. World J Gastroenterol 10(10): 1533-1536.

Daly C, Eichten A, Castanaro C, Pasnikowski E, Adler A, Lalani AS, Papadopoulos N, Kyle AH, Minchinton AI, Yancopoulos GD, Thurston G (2013) Angiopoietin-2 functions as a Tie2 agonist in tumor models, where it limits the effects of VEGF inhibition. Cancer Res 73(1): 108-118.

Dieci MV, Arnedos M, Andre F, Soria JC (2013) Fibroblast growth factor receptor inhibitors as a cancer treatment: from a biologic rationale to medical perspectives. Cancer Discov 3(3): 264-279.

Finn RS, Kang YK, Mulcahy M, Polite BN, Lim HY, Walters I, Baudelet C, Manekas D, Park JW (2012) Phase II, open-label study of brivanib as second-line therapy in patients with advanced hepatocellular carcinoma. Clin Cancer Res 18(7): 2090-2098.

Gauglhofer C, Sagmeister S, Schrottmaier W, Fischer C, Rodgarkia-Dara C, Mohr T, Stattner S, Bichler C, Kandioler D, Wrba F, Schulte-Hermann R, Holzmann K, Grusch M, Marian B, Berger W, Grasl-Kraupp B (2011) Up-regulation of the fibroblast growth factor 8 subfamily in human hepatocellular carcinoma for cell survival and neoangiogenesis. Hepatology 53(3): 854-864.

Guagnano V, Furet P, Spanka C, Bordas V, Le Douget M, Stamm C, Brueggen J, Jensen MR, Schnell C, Schmid H, Wartmann M, Berghausen J, Drueckes P, Zimmerlin A, Bussiere D, Murray J, Graus Porta D (2011) Discovery of 3-(2,6-dichloro-3,5-dimethoxy-phenyl)-1-\{6-[4-(4-ethylpiperazin-1-yl)-phenylamin o]-pyrimidin-4-yl\}-1-methyl-urea (NVPBGJ398), a potent and selective inhibitor of the fibroblast growth factor receptor family of receptor tyrosine kinase. J Med Chem 54(20): 7066-7083.

Harimoto N, Taguchi K, Shirabe K, Adachi E, Sakaguchi Y, Toh Y, Okamura T, Kayashima H, Taketomi A, Maehara Y (2010) The significance of fibroblast growth factor receptor 2 expression in differentiation of hepatocellular carcinoma. Oncology 78(5-6): 361-368.

Hernandez-Gea V, Toffanin S, Friedman SL, Llovet JM (2013) Role of the microenvironment in the pathogenesis and treatment of hepatocellular carcinoma. Gastroenterology 144(3): 512-527.

Hu CT, Cheng CC, Pan SM, Wu JR, Wu WS (2013) PKC mediates fluctuant ERK-paxillin signaling for hepatocyte growth factor-induced migration of hepatoma cell HepG2. Cell Signal 25(6): 1457-1467.

Huynh H, Chow KH, Soo KC, Toh HC, Choo SP, Foo KF, Poon D, Ngo VC, Tran E (2009) RAD001 (everolimus) inhibits tumour growth in xenograft models of human hepatocellular carcinoma. J Cell Mol Med 13(7): 1371-1380.

Jemal A, Bray F, Center MM, Ferlay J, Ward E, Forman D (2011) Global cancer statistics. CA Cancer J Clin 61(2): 69-90.

Kastanis GJ, Hernandez-Nazara Z, Nieto N, Rincon-Sanchez AR, Popratiloff A, Dominguez-Rosales JA, Lechuga CG, Rojkind M (2011) The role of dystroglycan in PDGF-BB-dependent migration of activated hepatic stellate cells/myofibroblasts. Am J Physiol Gastrointest Liver Physiol 301(3): G464-G474.

Lang SA, Gaumann A, Koehl GE, Seidel U, Bataille F, Klein D, Ellis LM, Bolder U, Hofstaedter F, Schlitt HJ, Geissler EK, Stoeltzing O (2007) Mammalian target of rapamycin is activated in human gastric cancer and serves as a target for therapy in an experimental model. Int $J$ Cancer 120(8): 1803-1810.

Lang SA, Hackl C, Moser C, Fichtner-Feigl S, Koehl GE, Schlitt HJ, Geissler EK, Stoeltzing O (2010) Implication of RICTOR in the mTOR inhibitor-mediated induction of insulin-like growth factor-I receptor (IGF-IR) and human epidermal growth factor receptor-2 (Her2) expression in gastrointestinal cancer cells. Biochim Biophys Acta 1803(4): 435-442.

Lang SA, Moser C, Fichnter-Feigl S, Schachtschneider P, Hellerbrand C, Schmitz V, Schlitt HJ, Geissler EK, Stoeltzing O (2009) Targeting heat-shock protein 90 improves efficacy of rapamycin in a model of hepatocellular carcinoma in mice. Hepatology 49(2): 523-532.

Lieu C, Heymach J, Overman M, Tran H, Kopetz S (2011) Beyond VEGF: inhibition of the fibroblast growth factor pathway and antiangiogenesis. Clin Cancer Res 17(19): 6130-6139.

Llovet JM, Decaens T, Raoul JL, Boucher E, Kudo M, Chang C, Kang YK, Assenat E, Lim HY, Boige V, Mathurin P, Fartoux L, Lin DY, Bruix J, Poon RT, Sherman M, Blanc JF, Finn R, Tak WY, Chao Y, Ezzeddine R, Liu D, Walters I, Park JW (2012) Brivanib Versus placebo in patients with advanced hepatocellular carcinoma (HCC) who failed or were intolerant to sorafenib: results from the Phase 3 Brisk-PS Study. J Hepatol 56: S549-S549.

Llovet JM, Ricci S, Mazzaferro V, Hilgard P, Gane E, Blanc JF, de Oliveira AC, Santoro A, Raoul JL, Forner A, Schwartz M, Porta C, Zeuzem S, Bolondi L, Greten TF, Galle PR, Seitz JF, Borbath I, Haussinger D, Giannaris T, Shan M, Moscovici M, Voliotis D, Bruix J (2008) Sorafenib in advanced hepatocellular carcinoma. N Engl J Med 359(4): 378-390.

Matter MS, Decaens T, Andersen JB, Thorgeirsson SS (2013) Targeting the mTOR pathway in hepatocellular carcinoma: current state and future trends. J Hepatol 60(4): 855-865.

Poon RT, Lau C, Pang R, Ng KK, Yuen J, Fan ST (2007) High serum vascular endothelial growth factor levels predict poor prognosis after radiofrequency ablation of hepatocellular carcinoma: importance of tumor biomarker in ablative therapies. Ann Surg Oncol 14(6): 1835-1845.

Poon RT, Ng IO, Lau C, Yu WC, Fan ST, Wong J (2001) Correlation of serum basic fibroblast growth factor levels with clinicopathologic features and postoperative recurrence in hepatocellular carcinoma. Am J Surg 182(3): 298-304.

Sarbassov DD, Guertin DA, Ali SM, Sabatini DM (2005) Phosphorylation and regulation of Akt/PKB by the rictor-mTOR complex. Science 307(5712): 1098-1101.

Taeger J, Moser C, Hellerbrand C, Mycielska ME, Glockzin G, Schlitt HJ, Geissler EK, Stoeltzing O, Lang SA (2011) Targeting FGFR/PDGFR/ VEGFR impairs tumor growth, angiogenesis, and metastasis by effects on tumor cells, endothelial cells, and pericytes in pancreatic cancer. Mol Cancer Ther 10(11): 2157-2167.

Talmadge JE, Singh RK, Fidler IJ, Raz A (2007) Murine models to evaluate novel and conventional therapeutic strategies for cancer. Am J Pathol 170(3): 793-804.

Wan X, Harkavy B, Shen N, Grohar P, Helman LJ (2007) Rapamycin induces feedback activation of Akt signaling through an IGF-1R-dependent mechanism. Oncogene 26(13): 1932-1940.

Wang YH, Dong YY, Wang WM, Xie XY, Wang ZM, Chen RX, Chen J, Gao DM, Cui JF, Ren ZG (2013) Vascular endothelial cells facilitated HCC invasion and metastasis through the Akt and NF-kappaB pathways induced by paracrine cytokines. J Exp Clin Cancer Res 32(1): 51.

Yao DF, Wu XH, Zhu Y, Shi GS, Dong ZZ, Yao DB, Wu W, Qiu LW, Meng XY (2005) Quantitative analysis of vascular endothelial growth factor, microvascular density and their clinicopathologic features in human hepatocellular carcinoma. Hepatobiliary Pancreat Dis Int 4(2): 220-226.

Yin C, Evason KJ, Asahina K, Stainier DY (2013) Hepatic stellate cells in liver development, regeneration, and cancer. J Clin Invest 123(5): 1902-1910.

Zhu AX, Duda DG, Sahani DV, Jain RK (2011) HCC and angiogenesis: possible targets and future directions. Nat Rev Clin Oncol 8(5): 292-301.

This work is published under the standard license to publish agreement. After 12 months the work will become freely available and the license terms will switch to a Creative Commons AttributionNonCommercial-Share Alike 4.0 Unported License.

Supplementary Information accompanies this paper on British Journal of Cancer website (http://www.nature.com/bjc) 